\title{
Serotonergic dysfunction: Brain imaging and behavioral correlates
}

\author{
JANA WRASE \\ Charité University Medicine Berlin, Berlin, Germany \\ MATTHIAS REIMOLD \\ University of Tübingen, Tübingen, Germany \\ and \\ IMKE PULS, THORSTEN KIENAST, and ANDREAS HEINZ \\ Charité University Medicine Berlin, Berlin, Germany
}

\begin{abstract}
Identification of gene-environment and gene-gene interactions has become increasingly important in understanding psychiatric disorders. Dysfunction of central serotonergic neurotransmission has been implicated in alcoholism, depression, and anxiety. We review the literature on nonhuman primates that assesses the interaction between the genetic constitution of the regulatory region of the serotonin transporter (5-HTT) and environmental factors. Prospective studies in nonhuman primates that underwent social stress found a reduction of the serotonin turnover rate among carriers of one or two short alleles in a functional polymorphism of the 5-HTT promoter. In these primates, brain imaging studies showed a relative increase in the availability of raphe serotonin transporters. A low serotonin turnover rate and a high availability of serotonin transporters were associated with reduced response to excessive alcohol intake, anxiety, and impulsive aggression. Animal experiments point to a relationship between serotonergic dysfunction, negative mood states, and excessive alcohol intake, which may in part be mediated by reduced alcohol-induced sedation.
\end{abstract}

Serotonergic pathways arise from the brain-stem raphe nuclei and innervate a multitude of brain areas, which may explain the variety of psychiatric disorders in which dysfunction of serotonergic neurotransmission has been implicated (Baumgarten \& Grozdanovic, 1997; Cloninger, 1987; Grove, Coplan, \& Hollander, 1997; Meltzer, Maes, \& Elkis, 1994; Owens \& Nemeroff, 1994). Once serotonin is released into the synaptic cleft, its reuptake is regulated by the availability and function of serotonin transporters. A functional polymorphism in the regulatory region of the serotonin transporter (5-HTT) gene has been associated with a twofold difference in serotonin reuptake rates and the risk to develop negative mood states (Caspi et al., 2003; Lesch et al., 1996). Besides negative mood states such as anxiety and depression (Artigas, 1995; L. C. Barr et al., 1994; Mann et al., 1996; Praag, 1977; TräskmanBendz, Åsberg, Bertilsson, \& Thorén, 1984), serotonergic dysfunction may also contribute to the pathogenesis and maintenance of excessive alcohol consumption and to impulsive behavior (Fils-Aime et al., 1996; Lemarquand, Pihl, \& Benkelfat, 1994). The acute response to alcohol is modulated both by the structure of the 5-HTT gene and by

Correspondence relating to this article may be sent to A. Heinz, Klinik für Psychiatrie und Psychotherapie, Charité Universitätsmedizin Berlin, CCM, Schumannstr. 20-21, 10117 Berlin, Germany (e-mail: andreas .heinz@charite.de). stress factors that affect the serotonin turnover rate and the in vivo availability of serotonin transporters (C. S. Barr et al., 2003; Doudet et al., 1995; Heinz et al., 1998; Hu et al., 2005; Schuckit et al., 1999). These observations may be relevant for the development of excessive alcohol intake and alcohol dependence, since a low level of response to acute alcohol intake is more common in the relatively alcohol-naive offspring of alcoholics and is predictive of subsequent alcohol abuse and dependence (Rodriguez, Wilson, \& Nagoshi, 1993; Schuckit et al., 1999; Schuckit \& Smith, 1996; Volavka et al., 1996). In this review, we will trace these lines of evidence and examine whether studies in nonhuman primates offer a coherent view of the behavioral correlates of serotonergic dysfunction.

\section{Genetic and Environmental Effects on Serotonergic Neurotransmission}

In humans and nonhuman primates, both genetic and environmental factors contribute to the serotonin turnover rate, as assessed by the serotonin metabolite 5-hydroxyindoleacetic acid (5-HIAA) in the cerebrospinal fluid (CSF; Clarke et al., 1996; Higley, Suomi, \& Linnoila, 1991; Higley et al., 1993; Oxenstierna et al., 1986; for a summary of the results from nonhuman primates, see Table 1). The central serotonin turnover rate and reuptake capacity can be assessed in vivo in nonhuman primates. Among adult primates, heritability of serotonin turnover accounted for $42 \%$ of the variance in CSF 5-HIAA concentrations (Kaplan et al., 2000). Among 


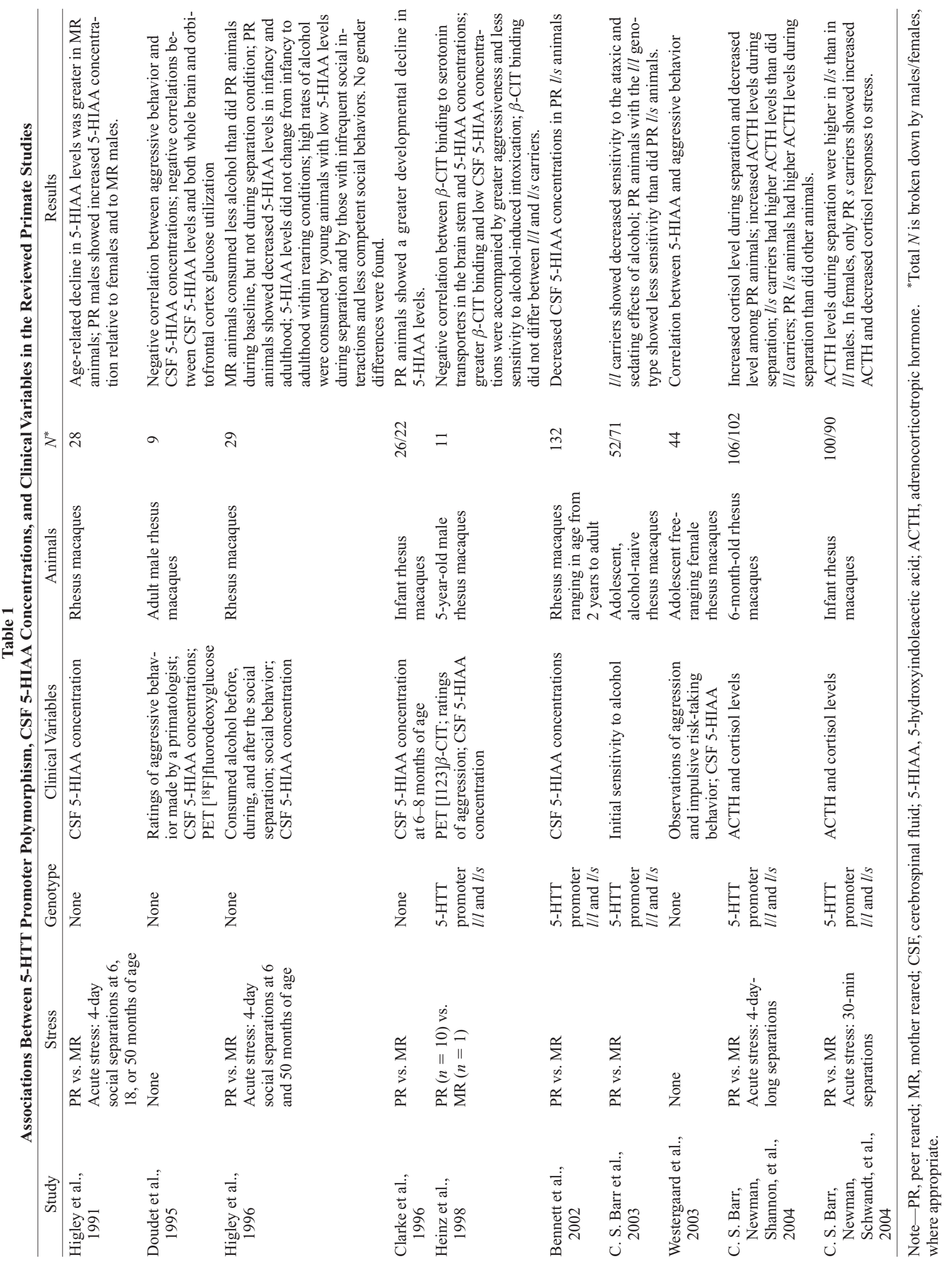


humans, heritability accounts for about $35 \%$ of this variance, and environmental factors play a very important role in the regulation of the serotonin turnover rate (Beck et al., 1984; Oxenstierna et al., 1986). Environmental factors are of special interest if they have long-lasting effects on serotonergic neurotransmission, as has been shown following early social separation stress (Clarke et al., 1996; Higley et al., 1991; G. H. Jones, Hernandez, Kendall, Marsden, \& Robbins, 1992).

Central serotonergic neurotransmission is also modulated by the functional capacity of serotonin transporters, which regulate reuptake of extracellular serotonin. Serotonin transporter expression and functional capacity are influenced by a variable number of tandem repeat polymorphic sites in the regulatory unit of the serotonin transporter gene (SLC6A4). Homozygous carriers of a long allele ( $l / l$ genotype) express about twice as many serotonin transporters as do carriers of one or two short alleles ( $s$ carriers; Heinz et al., 2000; Lesch et al., 1996; Little et al., 1998).

One environmental factor that has been examined in the context of gene-environment interaction and serotonin function is stress (see Table 1). A brain imaging study with SPECT and the radioligand $\beta$-CIT measured the availability of serotonin transporters in relation to CSF 5-HIAA concentrations. The study was performed with adult rhesus macaques who experienced social separation stress during their early development (Heinz et al., 1998; see Figure 1). Concentrations of the serotonin metabolite 5-HIAA in the CSF have been found to be reduced in primates that had been separated from their mothers after birth and peer-reared, in comparison with concentrations in mother-reared animals (Clarke et al., 1996; Higley, Suomi, \& Linnoila, 1996). CSF 5-HIAA levels decreased further when the primates were completely isolated from their peers within their early development (during the first 6 months of life). The reductions in CSF 5-HIAA concentrations were trait-like and persisted during adulthood (Heinz et al., 1998; Higley et al., 1996). During early social separation stress, rhesus macaques displayed increased anxiety-like behaviors (Higley et al., 1991), and during adulthood the male animals showed an increase in impulsive aggressiveness (Higley et al., 1996). In these primates, low CSF 5-HIAA concentrations were correlated with an increased availability of serotonin transporters in the brain stem (raphe) area (Heinz et al., 1998). Low CSF 5-HIAA concentrations and a high availability of brain-stem 5-HTT correlated with reduced time spent in social contacts and an increased frequency of self-initiated aggressive acts (Heinz et al., 1998). In female rhesus monkeys, low CSF 5-HIAA was associated with low-intensity, restrained aggression, which is typically observed in matrilineal defense of social status (Westergaard et al., 2003). Interestingly, the effects of early social isolation stress on CSF 5-HIAA concentrations seem to be modulated by the structure of the 5-HTT regulatory region. It has been observed that social isolation is followed by a reduction in the serotonin turnover rate in carriers of a short allele of the promoter of the 5-HTT gene, but not in homozygote carriers of two long alleles (Bennett et al., 2002). When these primates
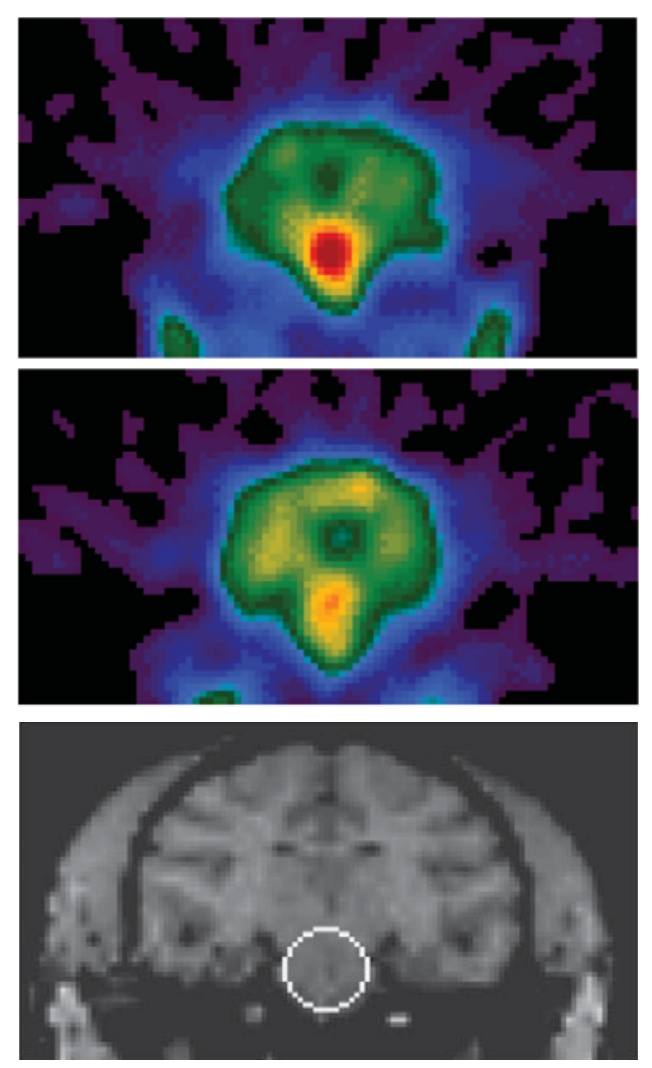

Figure 1. Serotonin transporter availability measured with $\beta$-CIT and SPECT in rhesus monkeys with and without early social isolation stress (coronal images). (Top) High serotonin transporter availability in an adult rhesus monkey who grew up without his mother (peer-reared). (Middle) Low serotonin transporter availability in an adult monkey who grew up with his mother (mother-reared). (Bottom) Placement of region of interest in the coregistered MRI in the brain-stem (raphe) area. From "In Vivo Association Between Alcohol Intoxication, Aggression, and Serotonin Transporter Availability in Nonhuman Primates" by A. Heinz, J. D. Higley, J. G. Gorey, R. C. Saunders, D. W. Jones, D. Hommer, et al., 1998, American Journal of Psychiatry, 155, p. 1025. Copyright 1998 by the American Psychiatric Association. Adapted with permission.

were exposed to complete social isolation during their early development (first 6 months of life), carriers of one short allele of the 5-HTT promoter showed higher concentrations of cortisol and adrenocorticotropine hormone $(\mathrm{ACTH})$ than did homozygote carriers of the long allele (C. S. Barr, Newman, Schwandt, et al., 2004). Increased stress-associated activation of the hypothalamic-pituitaryadrenal (HPA) axis may downregulate serotonin transporters (Slotkin, McCook, Ritchie, Carroll, \& Seidler, 1997). In accordance with this hypothesis, plasma cortisol concentrations were inversely correlated with the availability of brain-stem 5-HTT in healthy control subjects and male alcoholics, in whom stress may precipitate relapse to alcohol seeking (Heinz et al., 2002; see Figure 2).

The high availability of raphe serotonin transporters that was found in primates with low CSF 5-HIAA concentrations may be due to a real increase in serotonin transporter 


\section{Correlation Between Plasma Cortisol and Raphe Serotonin Transporters}

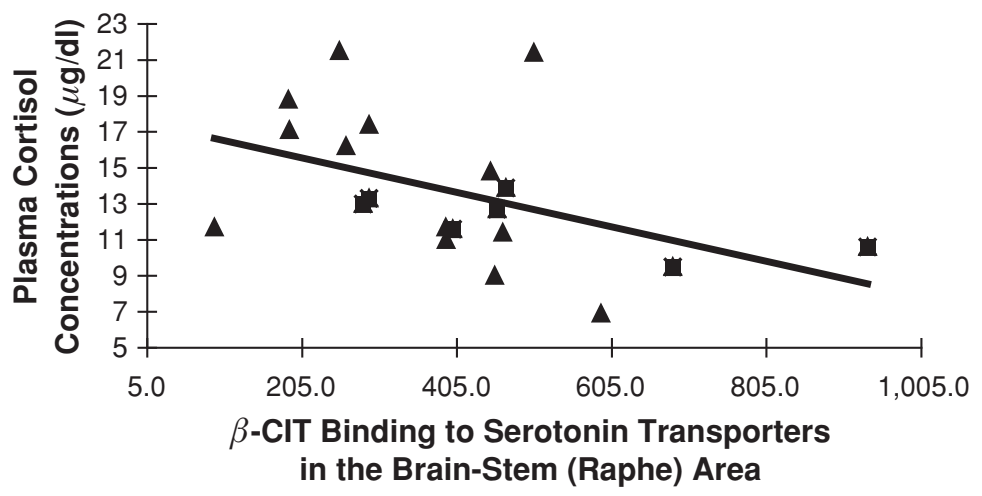

Figure 2. High cortisol concentrations (as found, e.g., during withdrawal stress) were correlated with low availability of brain-stem (raphe) serotonin transporters in male alcoholics (triangles) and healthy controls (squares). From "Relationship Between Cortisol and Serotonin Metabolites and Transporters in Alcoholism [Correction of Alcoholism]" by A. Heinz, D. W. Jones, G. Bissette, D. Hommer, P. Ragan, M. Knable, et al., 2002, Pharmacopsychiatry, 35, p. 131. Copyright 2002 by Georg Thieme Verlag. Adapted with permission.

density. An increase in functional reuptake capacity may be associated with reduced extracellular concentrations of monoamine neurotransmitters and their metabolites. Indeed, a postmortem study in nonhuman primates observed an increase in striatal dopamine transporter density in association with low concentrations of the dopamine metabolite homovanillic acid (Mash et al., 1996). Moreover, a combined microdialysis and $\beta$-CIT SPECT study revealed that the availability of monoamine uptake sites was inversely correlated with extracellular neurotransmitter concentrations (Heinz, 1999). Conversely, blockade or loss of dopamine or serotonin transporters induced an increase in extracellular neurotransmitter concentrations in animal models (Giros, Jaber, Jones, Wightman, \& Caron, 1996; Kreiss \& Lucki, 1995), confirming the hypothesis that the availability of monoamine transporters regulates extracellular monoamine concentrations. Alternatively, low extracellular 5-HIAA concentrations may be correlated with increased binding of $\beta$-CIT to serotonin transporters because of decreased competition of the radioligand with endogenous serotonin (D. W. Jones et al., 1998). In line with this hypothesis, restoration of synaptic serotonin concentrations to normal levels after depletion was associated with a significant reduction in $\beta$-CIT binding to raphe 5-HTT in nonhuman primates (Heinz et al., 2004). In any event, an increased availability of serotonin transporters, as assessed with $\beta$-CIT SPECT, was associated with low CSF 5-HIAA concentrations in humans and nonhuman primates (Heinz et al., 1998; Heinz et al., 2002; see Table 1).

\section{Secondary Behavioral Manifestations of Central Serotonergic Dysfunction}

Aggressive behavior may be a secondary or even primary correlate of reduced central serotonin turnover. It has been suggested that the experience of punishment is associated with a serotonergic activation of the septohippocampal behavior inhibition system, which is subjectively unpleasant and induces subsequent passive avoidance (Gray, 1982). Serotonergic dysfunction may thus be associated with a failure to activate the behavior inhibition system, which manifests as impulsiveness and uncontrolled aggressive behavior. An alternative hypothesis has been suggested, that impulsive aggressiveness is not a specific correlate of central serotonergic dysfunction and that a dysfunction of serotonergic neurotransmission is more credibly related to negative mood states such as anxiety or depression (Artigas, 1995; Knutson et al., 1998; Owens \& Nemeroff, 1994; Young, Warsh, Kish, Shannak, \& Hornykeiwicz, 1994). In accordance with this view, the pleasant psychopathological effects of "ecstasy" (methylenedioxymethamphetamine) have been associated with acute serotonin release (Huether, Zhou, \& Ruther, 1997). Moreover, improvement of negative mood states during medication with selective serotonin reuptake inhibitors (SSRIs) has been attributed to an increase rather than a decrease in synaptic serotonin concentrations, an observation that is difficult to reconcile with the notion of serotonergic neurotransmission stimulating a punishment system (Artigas, 1995; Kreiss \& Lucki, 1995; Limberger, Starke, \& Singer, 1990; Muck-Seler, Jevric-Causevic, \& Diksic, 1996). Furthermore, several studies have indicated that serotonin depletion induces negative mood states among patients with obsessive-compulsive disorder and in patients with major depression who previously responded to SSRI medication with a reduction in the severity of clinical depression (L. C. Barr et al., 1994; Delgado et al., 1990). These observations are in line with older human CSF studies, in which a significant association was observed between an increase in a primarily low CSF 
5-HIAA concentration and clinical remission of depressive symptoms (Praag, 1977; Träskman-Bendz et al., 1984). Together, these observations indicate that an increase in synaptic serotonin concentrations may not represent the neurobiological correlate of punishment but, rather, may induce a reduction in anxiety and depressiveness.

The associations between central serotonergic dysfunction and both negative mood states and impulsive aggression may derive from a common ground. Specifically, it has been argued that the association between a low serotonin turnover rate and aggressive behavior may be mediated by negative emotions such as feeling insecure and threatened (Heinz, Mann, Weinberger, \& Goldman, 2001). This hypothesis was based on a study by Knutson et al. (1998) in humans who engaged in a competitive game and received SSRI medication to induce an acute increase in synaptic serotonin concentrations. Knutson et al. (1998) found that the primary correlate of SSRI intake was a decrease in insecurity and anxiety, and the reduction in aggressive behavior was statistically explained by the decrease in negative emotions. The reduction in aggressiveness may thus be due to a decrease in perceptions of threat and insecurity. This interpretation is supported by animal experiments showing that serotonin depletion induces anxious and insecure behavior patterns (Knutson, Panksepp, Narayanan, \& Rossi, 1996), and increased serotonin turnover is associated with higher social competence in competitive games (Knutson, Panksepp, \& Pruitt, 1996).

A high serotonin turnover rate may protect against the impact of threat-related environmental cues: McCormick (1992) and Baumgarten and Grozdanovic (1995) have suggested that serotonergic neurotransmission supports a "protective filter effect" by modulating thalamo-cortical circuits, thus reducing the impact of sensory inputs. In light of this hypothesis, it is remarkable but counterintuitive that in humans, a genetic disposition for low serotonin transporter expression has been associated with an increased amygdala response to fearful faces and aversive stimuli (Hariri et al., 2002; Heinz et al., 2005). The exact interactions between human 5-HTT polymorphism, serotonin turnover rate, and anxiety require further examination.

Exacerbation of central serotonergic dysfunction during clinical disorders such as major depression may then lead to overactivation of the amygdala by aversive environmental stimuli, and indeed, increased glucose turnover rates were observed in depressed patients (Drevets, 2000). These observations suggest that serotonergic neurotransmission promotes a feeling of security and tranquility (Knutson, Panksepp, \& Pruitt, 1996; Raleigh, McGuire, \& Brammer, 1988), and that subjects with a deficit in serotonergic neurotransmission may feel insecure, anxious, and threatened (Clarke et al., 1996; Higley et al., 1991; Jones et al., 1992). In this view, the manifestation of aggressiveness or clinical depression after serotonin depletion is a secondary consequence from general feelings of tension and insecurity that manifest as negative mood states (Heinz et al., 2001; Knutson et al., 1998), which may depend upon the manifestation of other causal factors such as learned behavior in social contexts (Kraemer
\& McKinney, 1979; Raleigh \& McGuire, 1991). Further animal experiments and human studies in clinical populations will have to assess the interactions between serotonergic dysfunction, amygdala activation, and specific negative mood states.

\section{Serotonergic Neurotransmission and the Response to Acute Alcohol Intake}

Dysfunction of central serotonergic neurotransmission has long been suggested to characterize early-onset alcoholism with increased aggressiveness (Fils-Aime et al., 1996). Therefore, animal models were studied to elucidate the potential connection between serotonergic dysfunction, excessive alcohol intake, and aggressive behavior. In humans and nonhuman primates, subjects who show a low response to the effects of acute alcohol intake may lack a "warning signal" and tend to excessively consume alcohol, and indeed, a low alcohol response was associated in prospective human studies with excessive alcohol intake and increased risk to develop alcohol dependence (Schuckit et al., 1999; Schuckit \& Smith, 1996). Nonhuman primates that carried two long alleles of the 5-HTT promoter gene showed a low response to alcohol in comparison with carriers of one or two short alleles (C. S. Barr et al., 2003). An increase in serotonin transporter availability may also result from early social isolation stress: In nonhuman primates separated from their mothers after birth, a low serotonin turnover rate and high availability of raphe serotonin transporters were associated with a low response to the acute effects of alcohol intake (Heinz et al., 1998; see Figure 3). A dysfunction of central serotonergic neurotransmission may contribute to low alcohol response by reducing the sedative, GABAergic effects of alcohol in-

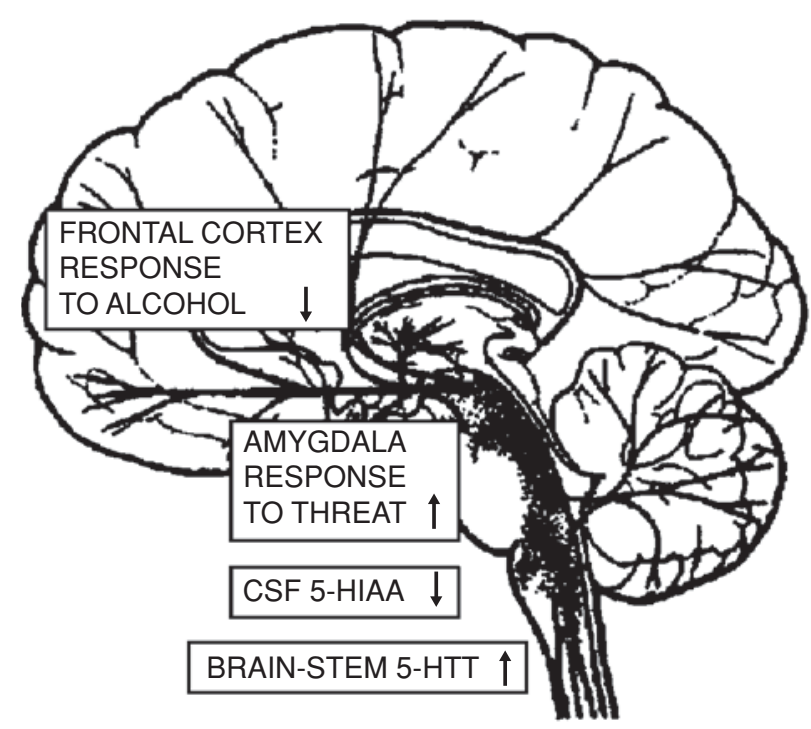

Figure 3. Alterations in serotonergic neurotransmission following early social separation stress. 5-HTT $s$ carriers may be specifically vulnerable to social isolation stress (Hartka et al., 1991) and may respond with an increase in serotonin transporter availability, a low serotonin turnover, an increased amygdala response to threat, and a low response to the acute effects of alcohol intake. 
take. GABA activation potentiates the sedative effects of ethanol, and GABAergic dysfunction has been associated with decreased sedative effects of alcohol (Liljequist \& Engel, 1982; Silveri \& Spear, 2002). Moreover, high doses of alcohol sedate via blockade of glutamatergic NMDA receptors (Krystal et al., 1998; Tsai, Gastfriend, \& Coyle, 1995). Reduced prefrontal serotonergic neurotransmission can interfere with both GABAergic and glutamatergic neurotransmission via $5-\mathrm{HT}_{1 \mathrm{~A}}$ and $5-\mathrm{HT}_{4}$ receptors (Cai, Flores-Hernandez, Feng, \& Yan, 2002; Cai, Gu, Zhong, Ren, \& Yan, 2002; Feng, Cai, Zhao, \& Yan, 2001; Krystal, Abi-Dargham, Laruelle, \& Moghaddam, 1999). In support of this hypothesis, Doudet et al. (1995) observed a significant correlation between CSF 5-HIAA concentrations and central effects of GABAergic drugs in nonhuman primates, so that prefrontal glucose utilization rates during GABAergic sedation were least affected in rhesus monkeys with the lowest CSF 5-HIAA concentrations. In a free choice paradigm, low CSF 5-HIAA concentrations and a high availability of serotonin transporters correlated with increased alcohol intake by nonhuman primates (Heinz, Schäfer, Higley, Krystal, \& Goldman, 2003).

\section{Disposition to Excessive Alcohol Intake: Gene-Environment Interactions As Mimicking Gene-Gene Interactions}

The predisposition for excessive alcohol intake is modulated by gene-environment interactions. In the nonhuman primate model of Higley et al. (1996), early social isolation stress was followed by (1) low levels of CSF 5-HIAA concentration, (2) a high availability of brainstem serotonin transporters, and (3) reduced drug-elicited GABAergic sedation (Doudet et al., 1995; Heinz et al., 1998). The constitution of serotonin transporters and $\mathrm{GABA}_{\mathrm{A}}$ receptors may result in a similar interaction between a high availability of central serotonin transporters and a low response of $\mathrm{GABA}_{\mathrm{A}}$ receptors: In two human studies, researchers observed that a low response to acute alcohol intake was associated with the 5-HTT $l / l$ genotype (Hu et al., 2005; Schuckit et al., 1999). Moreover, in humans, a low response to alcohol was associated with an allelic variant, Ser385, of the $\mathrm{GABA}_{\mathrm{A} \alpha 6}$ receptor polymorphism Pro385Ser (Schuckit et al., 1999). In rodents, a single-nucleotide mutation in the $\mathrm{GABA}_{\mathrm{A} \alpha 6}$ receptor subunit was also associated with a sensitivity to acute motorimpairing effects of moderate alcohol and benzodiazepine intake (Korpi, Kleingoor, Kettenmann, \& Seeburg, 1993). In a pilot study by Schuckit et al. (1999), all human subjects who carried the $l / l$ genotype of the 5-HTT promoter and the Pro/Ser genotype of the $\mathrm{GABA}_{\mathrm{A} \alpha 6}$ receptor subunit later became alcohol dependent. Together, these observations indicate that both genetic and environmental (stress) factors may interact with central serotonin turnover rates and the availability of serotonin transporters, interfere with the balance between glutamatergic excitation and GABAergic inhibition, and reduce the ataxic and sedative effects of acute alcohol intake (Heinz et al., 1998; Higley et al., 1996; Schuckit et al., 1999).
Inconsistent results were found in studies that assessed the potential association of serotonin transporter genotype with the risk to develop alcoholism (Edenberg et al., 1998; Gelernter, Kranzler, \& Cubells, 1997; Sander et al., 1998). Nonhuman primate studies suggest that environmental stress factors result in an interaction between serotonergic dysfunction and the alcohol response of $\mathrm{GABA}_{\mathrm{A}}$ receptors that mimics genetic effects on serotonin transporters and GABAergic neurotransmission. In Bennett et al. (2002), exposure to early social isolation stress reduced CSF 5-HIAA concentrations in nonhuman primates that had one or two short alleles of the 5-HTT regulatory unit, but it did not interact with CSF 5-HIAA concentrations in the $l / l$ genotype. The primates examined in Heinz et al. (1998) were mostly carriers of the "stress-vulnerable" genotype with one or two short alleles of the 5-HTT regulatory unit. In this genotype, a high availability of brain-stem serotonin transporters may result from stress-induced decreases in central serotonin turnover (Bennett et al., 2002; Heinz et al., 1998), but in the $l / l$ genotype, a high availability of central serotonin transporters is due mainly to genetic factors (Lesch et al., 1996). Independent of its genetic or environmental causation, the resulting high availability of brain-stem serotonin transporters may contribute to a low response to alcohol intake and to excessive alcohol consumption (C. S. Barr et al., 2003; Heinz et al., 1998).

Moreover, 5-HTT $s$ carriers may be specifically vulnerable to social isolation stress and may react with increased HPA-axis activation and negative mood states such as clinical depression or anxiety, factors that may also contribute to excessive alcohol intake in humans (Hartka et al., 1991). Although anxiety was only slightly increased in healthy human volunteers who carried one or two short alleles of the 5-HTT regulatory unit (Lesch et al., 1996), subjects with this genotype displayed increased amygdala activation when confronted with fearful faces (Hariri et al., 2002; Heinz et al., 2005) and showed increased occurrence of clinical depression when they had been exposed to abuse during early childhood (Caspi et al., 2003). Interestingly, nonhuman primates showed a gender-specific interaction between early social isolation stress and HPA-axis activation during further stress exposure in a study by C. S. Barr, Newman, Schwandt, et al. (2004). In this study, female and male rhesus monkeys were exposed to early social separation stress and either were peer-reared (PR) or grew up with their mothers (MR). When subjected to complete social isolation, male carriers of one short allele of the 5-HTT gene displayed increased ACTH concentrations compared with $l$ homozygotes, and this increase was independent of whether they were PR or MR. In female primates, an increase in cortisol concentrations in $s$ carriers compared with $l$ homozygotes was only found in PR monkeys - that is, in those who had experienced early adversity in the form of social separation stress. Further studies will have to examine the interaction between gender, 5-HTT genotype, and the behavioral correlates of stress-associated changes in serotonin turnover and HPA-axis activation. 


\section{Conclusion}

Current studies suggest that 5-HTT genotype mediates the impact of early social separation stress on the central serotonin turnover rate and the activation of the stress hormone axis in nonhuman primates, and potentially also in humans (C. S. Barr, Newman, Schwandt, et al., 2004; Bennett et al., 2002). In nonhuman primates, social separation stress has been associated with a low serotonin turnover rate and associated changes in the availability of central serotonin transporters (Heinz et al., 1998; Higley et al., 1996). Among these subjects, a low serotonin turnover rate and high availability of brain-stem serotonin transporters correlated with increased anxiety, impulsive aggression, and low response to alcohol (Heinz et al., 1998; Higley et al., 1991). A low response to ethanol and increased aggressiveness was also found in mice lacking the 5-HT ${ }_{1 \mathrm{~B}}$ receptor (Coccaro et al., 1989; Saudou et al., 1994). In a series of human studies, a low serotonin turnover rate was associated with anxious behavior and perceptions of threat, which may secondarily have contributed to impulsive aggression (Knutson et al., 1998; Meltzer et al., 1994; Praag, 1977). Conversely, in healthy human volunteers, increased amygdala activation elicited by aversive stimuli was found in carriers of a short allele of the promoter of the serotonin transporter gene. These subjects also displayed increased activation of the medial prefrontal cortex, an area that may contribute to emotion regulation (Heinz et al., 2005; Pezawas et al., 2005). In nonhuman primate studies, $s$ carriers were specifically vulnerable to social isolation stress and displayed significant reductions in the central serotonin turnover rate (Bennett et al., 2002). In a human study, $s$ carriers who had experienced a high number of traumatizing events displayed a higher risk to develop negative mood states such as major depression (Caspi et al., 2003). It is possible that in these subjects, a stress-related reduction in central serotonin turnover may have interfered with the 5-HTT-genotype-driven interaction between the amygdala and the medial prefrontal cortex, thus impairing prefrontal emotional control, but this hypothesis has so far not been tested in humans. On the basis of the available primate studies, gender effects may also play a role in humans and influence whether serotonin dysfunction results in negative mood states or impulsive aggression (C. S. Barr, Newman, Schwandt, et al., 2004; Heinz et al., 1998).

Further studies are required in order to examine the relationship between these behavioral phenotypes, serotonergic dysfunction and genotype, and the pathogenesis and maintenance of clinical disorders such as major depression and alcoholism.

\section{REFERENCES}

Artigas, F. (1995). Pindolol, 5-hydroxytryptamine, and antidepressant augmentation. Archives of General Psychiatry, 52, 969-971.

Barr, C. S., Newman, T. K., Becker, M. L., Champoux, M., Lesch, K.-P., SuOMI, S. J., ET AL. (2003). Serotonin transporter gene variation is associated with alcohol sensitivity in rhesus macaques exposed to early-life stress. Alcoholism: Clinical \& Experimental Research, 27, 812-817.
Barr, C. S., Newman, T. K., Schwandt, M., Shannon, C., Dvoskin, R. L., Lindell, S. G., ET AL. (2004). Sexual dichotomy of an interaction between early adversity and the serotonin transporter gene promoter variant in rhesus macaques. Proceedings of the $\mathrm{Na}$ tional Academy of Sciences, 101, 12358-12363.

Barr, C. S., Newman, T. K., Shannon, C., Parker, C., Dvoskin, R. L., BECKER, M. L., ET AL. (2004). Rearing condition and rh5-HTTLPR interact to influence limbic-hypothalamic-pituitary-adrenal axis response to stress in infant macaques. Biological Psychiatry, 55, 733738.

Barr, L. C., Goodman, W. K., McDougle, C. J., Delgado, P. L., Heninger, G. R., Charney, D. S., \& Price, L. H. (1994). Tryptophan depletion in patients with obsessive-compulsive disorder who respond to serotonin reuptake inhibitors. Archives of General Psychiatry, 51, 309-317.

Baumgarten, H. G., \& Grozdanovic, Z. (1995). Psychopharmacology of central serotonergic systems. Pharmacopsychiatry, 28(Suppl. 2), 73-79.

Baumgarten, H. G., \& Grozdanovic, Z. (1997). Anatomy of central serotoninergic projection systems. In H. G. Baumgarten \& M. Göthert (Eds.), Handbook of experimental pharmacology: Vol. 129. Serotoninergic neurons and 5-HT receptors in the CNS (pp. 41-89). Berlin: Springer.

Beck, O., Borg, S., Edman, G., Fyro, B., Oxenstierna, G., \& SedVALL, G. (1984). 5-Hydroxytryptophol in human cerebrospinal fluid: Conjugation, concentration gradient, relationship to 5-hydroxyindoleacetic acid, and influence of hereditary factors. Journal of Neurochemistry, 43, 58-61.

Bennett, A. J., Lesch, K.-P., Heils, A., Long, J. C., Lorenz, J. G., SHOAF, S. E., ET AL. (2002). Early experience and serotonin transporter gene variation interact to influence primate CNS function. Molecular Psychiatry, 7, 118-122.

Cai, X. [A.], Flores-Hernandez, J., Feng, J., \& Yan, Z. (2002). Activity-dependent bidirectional regulation of $\operatorname{GABA}(\mathrm{A})$ receptor channels by the 5 -HT(4) receptor-mediated signalling in rat prefrontal cortical pyramidal neurons. Journal of Physiology, 540, 743-759.

CaI, X. A., Gu, Z. L., Zhong, P., Ren, Y., \& Yan, Z. (2002). Serotonin 5-HT1A receptors regulate AMPA receptor channels through inhibiting $\mathrm{Ca} 2+/$ calmodulin-dependent kinase II in prefrontal cortical pyramidal neurons. Journal of Biological Chemistry, 277, 36553-36562.

Caspi, A., Sugden, K., Moffitt, T. E., Taylor, A., Craig, I. W., HarRINGTON, H., ET AL. (2003). Influence of life stress on depression: Moderation by a polymorphism in the 5-HTT gene. Science, $\mathbf{3 0 1}$, 386-389.

Clarke, A. S., Hedeker, D. R., Ebert, M. H., Schmidt, D. E., McKinney, W. T., \& Kraemer, G. W. (1996). Rearing experience and biogenic amine activity in infant rhesus monkeys. Biological Psychiatry, 40, 338-352.

Cloninger, C. R. (1987). A systematic method for clinical description and classification of personality variants: A proposal. Archives of General Psychiatry, 44, 573-588.

Coccaro, E. F., Siever, L. J., Klar, H. M., Maurer, G., Cochrane, K., COOPER, T. B., ET AL. (1989). Serotonergic studies in patients with affective and personality disorders: Correlates with suicidal and impulsive aggressive behavior. Archives of General Psychiatry, 46, 587-599.

Delgado, P. L., Charney, D. S., Price, L. H., Aghajanian, G. K., Landis, H., \& Heninger, G. R. (1990). Serotonin function and the mechanism of antidepressant action: Reversal of antidepressantinduced remission by rapid depletion of plasma tryptophan. Archives of General Psychiatry, 47, 411-418.

Doudet, D., Hommer, D., Higley, J. D., Andreason, P. J., Moneman, R., Suomi, S. J., \& Linnoila, M. (1995). Cerebral glucose metabolism, CSF 5-HIAA levels, and aggressive behavior in rhesus monkeys. American Journal of Psychiatry, 152, 1782-1787.

Drevets, W. C. (2000). Neuroimaging studies of mood disorders. Biological Psychiatry, 48, 813-829.

Edenberg, H. J., Reynolds, J., Koller, D. L., Begleiter, H., BuchOlz, K. K., Conneally, P. M., ET AL. (1998). A family-based analysis of whether the functional promoter alleles of the serotonin transporter gene HTT affect the risk for alcohol dependence. Alcoholism. Clinical \& Experimental Research, 22, 1080-1085. 
FenG, J., CaI, X., ZhaO, J. H., \& Yan, Z. (2001). Serotonin receptors modulate GABA(A) receptor channels through activation of anchored protein kinase $\mathrm{C}$ in prefrontal cortical neurons. Journal of Neuroscience, 21, 6502-6511.

Fils-Aime, M.-L., Eckardt, M. J., George, D. T., Brown, G. L., MefFORD, I., \& LinNoILA, M. (1996). Early-onset alcoholics have lower cerebrospinal fluid 5-hydroxyindoleacetic acid levels than late-onset alcoholics. Archives of General Psychiatry, 53, 211-216.

Gelernter, J., Kranzler, H., \& Cubells, J. F. (1997). Serotonin transporter protein (SLC6A4) allele and haplotype frequencies and linkage disequilibria in African- and European-American and Japanese populations and in alcohol-dependent subjects. Human Genetics, 101, 243-246.

Giros, B., Jaber, M., Jones, S. R., Wightman, R. M., \& Caron, M. G. (1996). Hyperlocomotion and indifference to cocaine and amphetamine in mice lacking the dopamine transporter. Nature, 379, 606-612.

GraY, J. (1982). The neuropsychology of anxiety: An inquiry into the function of the septo-hippocampal system. New York: Oxford University Press.

Grove, G., Coplan, J. D., \& Hollander, E. (1997). The neuroanatomy of 5-HT dysregulation and panic disorder. Journal of Neuropsychiatry and Clinical Neurosciences, 9, 198-207.

Hariri, A. R., Mattay, V. S., Tessitore, A., Kolachana, B., Fera, F., Goldman, D., ET AL. (2002). Serotonin transporter genetic variation and the response of the human amygdala. Science, 297, 400-403.

Hartia, E., Johnstone, B., Leino, E. V., Motoyoshi, M., Temple, M. T., \& Fillmore, K. M. (1991). A meta-analysis of depressive symptomatology and alcohol consumption over time. British Journal of Addiction, 86, 1283-1298.

HeInZ, A. (1999). Neurobiological and anthropological aspects of compulsions and rituals. Pharmacopsychiatry, 32, 223-229.

Heinz, A., Braus, D. F., Smolka, M. N., Wrase, J., Puls, I., Hermann, D., ET AL. (2005). Amygdala-prefrontal coupling depends on a genetic variation of the serotonin transporter. Nature Neuroscience, 8, 20-21.

Heinz, A., Higley, J. D., Gorey, J. G., Saunders, R. C., Jones, D. W., Hommer, D., ET AL. (1998). In vivo association between alcohol intoxication, aggression, and serotonin transporter availability in nonhuman primates. American Journal of Psychiatry, 155, 1023-1028.

Heinz, A., Jones, D. W., Bissette, G., Hommer, D., Ragan, P., KNABLE, M., ET AL. (2002). Relationship between cortisol and serotonin metabolites and transporters in alcoholism [correction of alcoholism]. Pharmacopsychiatry, 35, 127-134.

Heinz, A., Jones, D. W., Mazzanti, C., Goldman, D., Ragan, P., Hommer, D., ET AL. (2000). A relationship between serotonin transporter genotype and in vivo protein expression and alcohol neurotoxicity. Biological Psychiatry, 47, 643-649.

Heinz, A., Jones, D. W., ZaJiceK, K., Gorey, J. G., Juckel, G., HigLEY, J. D., \& Weinberger, D. R. (2004). Depletion and restoration of endogenous monoamines affects beta-CIT binding to serotonin but not dopamine transporters in non-human primates. Journal of Neural Transmission: Supplementum, 68, 29-38.

Heinz, A., Mann, K., Weinberger, D. R., \& Goldman, D. (2001). Serotonergic dysfunction, negative mood states, and response to alcohol. Alcoholism: Clinical \& Experimental Research, 25, 487-495.

Heinz, A., Schäfer, M., Higley, J. D., Krystal, J. H., \& Goldman, D. (2003). Neurobiological correlates of the disposition and maintenance of alcoholism. Pharmacopsychiatry, 36(Suppl. 3), S255-S258.

Higley, J. D., Suomi, S. J., \& Linnolla, M. (1991). CSF monoamine metabolite concentrations vary according to age, rearing, and sex, and are influenced by the stressor of social separation in rhesus monkeys. Psychopharmacology, 103, 551-556.

Higley, J. D., Suomi, S. J., \& Linnoila, M. (1996). A nonhuman primate model of type II excessive alcohol consumption? Part 1. Low cerebrospinal fluid 5-hydroxyindoleacetic acid concentrations and diminished social competence correlate with excessive alcohol consumption. Alcoholism: Clinical \& Experimental Research, 20, 629-642.

Higley, J. D., Thompson, W. W., Champoux, M., Goldman, D., Hasert, M. F., Kraemer, G. W., et al. (1993). Paternal and maternal genetic and environmental contributions to cerebrospinal fluid monoamine metabolites in rhesus monkeys (Macaca mulatta). $\mathrm{Ar}$ chives of General Psychiatry, 50, 615-623.

Hu, X., Oroszi, G., Chun, J., Smith, T. L., Goldman, D., \& Schuck-
IT, M. A. (2005). An expanded evaluation of the relationship of four alleles to the level of response to alcohol and the alcoholism risk. Alcoholism: Clinical \& Experimental Research, 29, 8-16.

Huether, G., Zhou, D., \& Ruther, E. (1997). Causes and consequences of the loss of serotonergic presynapses elicited by the consumption of 3,4-methylenedioxymethamphetamine (MDMA, "ecstasy") and its congeners. Journal of Neural Transmission, 104, 771-794.

Jones, D. W., Gorey, J. G., Zajicek, K., Das, S., Urbina, R. A., LEE, K. S., ET AL. (1998). Depletion-restoration studies reveal the impact of endogenous dopamine and serotonin on [1123] $\beta$-CIT SPECT imaging in primate brain [Abstract]. Journal of Nuclear Medicine, 39, 42 .

Jones, G. H., Hernandez, T. D., Kendall, D. A., Marsden, C. A., \& RobBins, T. W. (1992). Dopaminergic and serotonergic function following isolation rearing in rats: Study of behavioural responses and postmortem and in vivo neurochemistry. Pharmacology, Biochemistry, \& Behavior, 43, 17-35.

Kaplan, J. R., Martin, L. J., Comuzzie, A. G., Manuck, S. B., MANN, J. J., \& Rogers, J. (2000). Heritability of monoaminergic metabolites measured in the cerebrospinal fluid of baboons. Social Neuroscience Abstracts, 26, 1439.

Knutson, B., Panksepp, J., Narayanan, T. K., \& Rossi, J., III (1996). Early central serotonin damage increases "anxious" behaviors in juvenile rats. Society for Neuroscience Abstracts, 22, 446.

Knutson, B., PAnksepp, J., \& Pruitt, D. (1996). Effects of fluoxetine on play dominance in juvenile rats. Aggressive Behavior, 22, 297-307.

Knutson, B., Wolkowitz, O. M., Cole, S. W., Chan, T., Moore, E. A., JoHNSON, R. C., ET AL. (1998). Selective alteration of personality and social behavior by serotonergic intervention. American Journal of Psychiatry, 155, 373-379.

Korpi, E. R., Kleingoor, C., Kettenmann, H., \& Seeburg, P. H. (1993). Benzodiazepine-induced motor impairment linked to point mutation in cerebellar GABA(A) receptor. Nature, 361, 356-359.

Kraemer, G. W., \& McKinney, W. T. (1979). Interactions of pharmacological agents which alter biogenic amine metabolism and depression: An analysis of contributing factors within a primate model of depression. Journal of Affective Disorders, 1, 33-54.

KrEISS, D. S., \& LUCKI, I. (1995). Effects of acute and repeated administration of antidepressant drugs on extracellular levels of 5hydroxytryptamine measured in vivo. Journal of Pharmacology \& Experimental Therapeutics, 274, 866-876.

Krystal, J. H., Abi-Dargham, A., Laruelle, M., \& Moghaddam, B. (1999). Pharmacological models of psychosis. In D. S. Charney, E. J. Nestler, \& B. S. Bunney (Eds.), Neurobiology of mental illness (pp. 214-224). New York: Oxford University Press.

Krystal, J. H., Petrakis, I. L., Webb, E., Cooney, N. L., Karper, L. P. NAmAnworth, S., ET AL. (1998). Dose-related ethanol-like effects of the NMDA antagonist, ketamine, in recently detoxified alcoholics. Archives of General Psychiatry, 55, 354-360.

Lemarquand, D., Pihl, R. O., \& BenKelfat, C. (1994). Serotonin and alcohol intake, abuse, and dependence: Findings of animal studies. Biological Psychiatry, 36, 395-421.

Lesch, K.-P., Bengel, D., Heils, A., Sabol, S. Z., Greenberg, B. D., Petri, S., ET AL. (1996). Association of anxiety-related traits with a polymorphism in the serotonin transporter gene regulatory region. Science, 274, 1527-1531.

LILJEQUist, S., \& ENGEL, J. (1982). Effects of GABAergic agonists and antagonists on various ethanol-induced behavioral changes. Psychopharmacology, 78, 71-75.

Limberger, N., Starke, K., \& Singer, E. A. (1990). Serotonin uptake blockers influence serotonin autoreceptors by increasing the biophase concentration of serotonin and not through a "molecular link." Naunyn-Schmiedeberg's Archives of Pharmacology, 342, 363-370.

Little, K. Y., Mclaughlin, D. P., Zhang, L., Livermore, C. S., Dalack, G. W., McFinton, P. R., ET AL. (1998). Cocaine, ethanol, and genotype effects on human midbrain serotonin transporter binding sites and mRNA levels. American Journal of Psychiatry, 155, 207-213.

Mann, J. J., Malone, K. M., Sweeney, J. A., Brown, R. P., Linnoila, M., Stanley, B., \& Stanley, M. (1996). Attempted suicide characteristics and cerebrospinal fluid amine metabolites in depressed inpatients. Neuropsychopharmacology, 15, 576-586.

Mash, D. C., Staley, J. K., Doepel, F. M., Young, S. N., Ervin, F. R., 
\& Palmour, R. M. (1996). Altered dopamine transporter densities in alcohol-preferring vervet monkeys. NeuroReport, 7, 457-462.

McCormick, D. A. (1992). Neurotransmitter actions in the thalamus and cerebral cortex. Journal of Clinical Neurophysiology, 9, 212-223.

Meltzer, H., Maes, M., \& ElKis, H. (1994). The biological basis of refractory depression. In W. Nolen, J. Zohar, S. Roose, \& J. Amsterdam (Eds.), Refractory depression: Current strategies and future directions (pp. 177-198). Chichester, U.K.: Wiley.

Muck-Seler, D., Jevric-CAusevic, A., \& Diksic, M. (1996). Influence of fluoxetine on regional serotonin synthesis in the rat brain. Journal of Neurochemistry, 67, 2434-2442.

Owens, M. J., \& Nemeroff, C. B. (1994). Role of serotonin in the pathophysiology of depression: Focus on the serotonin transporter. Clinical Chemistry, 40, 288-295.

Oxenstierna, G., Edman, G., Iselius, L., Oreland, L., Ross, S. B., \& Sedvall, G. (1986). Concentrations of monoamine metabolites in the cerebrospinal fluid of twins and unrelated individuals - A genetic study. Journal of Psychiatric Research, 20, 19-29.

Pezawas, L., Meyer-Lindenberg, A., Drabant, E. M., VerchinSKI, B. A., MunOz, K. E., Kolachana, B. S., ET AL. (2005). 5-HTTLPR polymorphism impacts human cingulate-amygdala interactions: A genetic susceptibility mechanism for depression. Nature Neuroscience, 8, 828-834.

PraAg, H. (1977). The Harold E. Himwich Memorial Lecture. Significance of biochemical parameters in the diagnosis, treatment, and prevention of depressive disorders. Biological Psychiatry, 12, 101-131.

Raleigh, M. J., \& McGuire, M. T. (1991). Bidirectional relationship between tryptophan and social behavior in vervet monkeys. In R. Schwarcz, S. N. Young, \& R. R. Brown (Eds.), Kynurenine and serotonin pathways: Progress in tryptophan research (pp. 289-298). New York: Plenum.

Raleigh, M. J., McGuire, M. T., \& Brammer, G. L. (1988). Behavioral and cognitive effects of altered tryptophan and tyrosine supply. In G. Huether (Ed.), Amino acid availability and brain function in health and disease (pp. 299-308). Berlin: Springer.

Rodriguez, L. A., Wilson, J. R., \& NAgoshi, C. T. (1993). Does psychomotor sensitivity to alcohol predict subsequent alcohol use? Alcoholism: Clinical \& Experimental Research, 17, 155-161.

Sander, T., Harms, H., Dufeu, P., Kuhn, S., Hoehe, M., Lesch, K.-P., ET AL. (1998). Serotonin transporter gene variants in alcohol- dependent subjects with dissocial personality disorder. Biological Psychiatry, 43, 908-912.

Saudou, F., Amara, D. A., Dierich, A., LeMeur, M., Ramboz, S., SEGU, L., ET AL. (1994). Enhanced aggressive behavior in mice lacking 5-HT1B receptor. Science, 265, 1875-1878.

Schuckit, M. A., Mazzanti, C., Smith, T. L., Ahmed, U., Radel, M., Iwata, N., \& Goldman, D. (1999). Selective genotyping for the role of 5-HT2A, 5-HT2C, and GABA(alpha 6) receptors and the serotonin transporter in the level of response to alcohol: A pilot study. Biological Psychiatry, 45, 647-651.

SchUCKIT, M. A., \& SмITH, T. L. (1996). An 8-year follow-up of 450 sons of alcoholic and control subjects. Archives of General Psychiatry, 53, 202-210.

Silveri, M. M., \& Spear, L. P. (2002). The effects of NMDA and GABA(A) pharmacological manipulations on ethanol sensitivity in immature and mature animals. Alcoholism: Clinical \& Experimental Research, 26, 449-456.

Slotkin, T. A., McCook, E. C., Ritchie, J. C., Carroll, B. J., \& SEIDLER, F. J. (1997). Serotonin transporter expression in rat brain regions and blood platelets: Aging and glucocorticoid effects. Biological Psychiatry, 41, 172-183.

Träskman-Bendz, L., Åsberg, M., Bertilsson, L., \& Thorén, P. (1984). CSF monoamine metabolites of depressed patients during illness and after recovery. Acta Psychiatrica Scandinavica, 69, 333-342.

Tsai, G. C., Gastfriend, D. R., \& Coyle, J. T. (1995). The glutamatergic basis of human alcoholism. American Journal of Psychiatry, 152, 332-340.

Volavka, J., Czobor, P., Goodwin, D. W., Gabrielli, W. F., Jr., Penick, E. C., Mednick, S. A., ET AL. (1996). The electroencephalogram after alcohol administration in high-risk men and the development of alcohol use disorders 10 years later: Preliminary findings. Archives of General Psychiatry, 53, 258-263.

Westergaard, G. C., Suomi, S. J., Chavanne, T. J., Houser, L., HurLey, A., Cleveland, A., ET AL. (2003). Physiological correlates of aggression and impulsivity in free-ranging female primates. Neuropsychopharmacology, 28, 1045-1055.

Young, L. T., Warsh, J. J., Kish, S. J., Shannak, K., \& HornykeIwICZ, O. (1994). Reduced brain 5-HT and elevated NE turnover and metabolites in bipolar affective disorder. Biological Psychiatry, 35, 121-127. 